\title{
An ontology driven question answering system for fatawa retrieval
}

\author{
Benlaharche Keltoum ${ }^{1}$, Zakaria Laboudi ${ }^{2}$, Nabila Nouaouria ${ }^{3}$, Djamel Eddine Zegour ${ }^{4}$ \\ ${ }^{1}$ Department of mathematics and computer sciences, University of Oum El Bouaghi, Algeria \\ ${ }^{2}$ Research laboratory on computer science's complex systems, University of Oum El Bouaghi, Algeria \\ ${ }^{3}$ Laboratory of Complex Systems, Badji Mokhtar University, Algeria \\ ${ }^{4}$ LCSI Laboratory, Ecole nationale Supérieure d'Informatique ESI, Algeria
}

\begin{abstract}
Article Info
Article history:

Received Jan 2, 2021

Revised Jun 30, 2021

Accepted Jul 7, 2021

\section{Keywords:}

Case based-reasoning

Domain ontology

Expert mufti

Fatawa support

Information retrieval

Question answering systems

ABSTRACT

This work aims to propose a system for the Algerian Fatawa House in order to facilitate the task of the Expert Mufti who is responsible of giving fatawa for Algerian people inquiries. In fact, as this house is recent and does not have sufficient human resources, it is difficult to satisfy all inquiries coming daily; this leads the askers to wait for a long time before getting answers. The proposed system allows the askers to express concerns they may have. By using a case-based reasoning mechanism combined with ontology domain, the system tries to retrieve similar cases from the knowledge base. In the case where the response already exists, the system immediately provides the answer to the askers. Otherwise, an inquery is automatically formulated and sent to the expert Mufti-which is a certified scholar-in order either to validate the generated response by the system or give a new answer. Such a questionanswering system may be very helpful for askers to get their answers faster since it allows both the storage of previous fatawas and their retrieval for processing coming inquiries. To validate our proposal, we rely on fatawas concerning the Islamic finance and banking transactions domain. Overall, the results are encouraging and satisfactory.
\end{abstract}

This is an open access article under the CC BY-SA license.

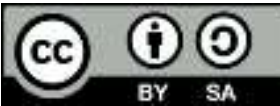

\section{Corresponding Author:}

Benlaharche Keltoum

Department of mathematics and computer sciences

University of Oum El Bouaghi

B.P.358 route de Constantine, Oum El Bouaghi 04000, Algérie

Email: benlaharche.keltoum@gmail.com

\section{INTRODUCTION}

In 2017, the Algerian government restore "the Fatawa house" after a long time of inactivity since the independence in 1962. This house is an official organization that provides Fatawa (answers) for requests of the Algerian people. In Islamic legislation, a Fatwa (singular of fatawa or fatawas) consists in a declaration of a legal opinion that complies with Islamic precepts. A Fatwa is a legal statement in Islam, generated by a Mufti or a religious lawyer, on a specific issue. Fatawas are asked by judges or individuals in cases where an issue of Figh is undecided or uncertain. Lawsuits can be settled on the basis of a fatwa [1].

According to "Algerian Fatwa house", there is still a lack of an automated system for storing and retrieving answered fatawa. Indeed, every day, the house receives a large number of questions through different methods (e.g., phone, fax and web site), some of which have already been asked before. In fact, as the house does not include sufficient human resources, it is very difficult to satisfy all these fatawa requests in particular since its activity only started three years ago. Thus, the task of the Expert Mufti becomes very 
difficult given that he is the only responsible of giving answers (fatawa) to all the questions received, especially that he manages other tasks (e.g., teaching at the university, and religious duties).

Starting from that context, we propose an efficient automatic question-answering system to process Fatawa requests through answers and arguments from Quran, Sunnah and Ijtihad. The idea consists in building an intelligent case-based system that can store previous fatawa and retrieve them as needed. The need for submitting requests can be optimized since similar requests are already processed by recording their answers in the knowledge base. In this way, the Expert Scholars will only focus on the new issues. This makes the organization handle more and more users without human intervention while increasing the ability to answer inquiries. Certainly, this helps both asker and the Expert Mufti in saving effort and time while processing inquiries.

For this purpose, the case-based reasoning (CBR) paradigm is involved. It is considered as one of the most popular approaches for developing knowledge-based systems due to its ability to retrieve and reuse solutions that have worked for similar situations in the past. This principle is similar to the way the human solves problems [2]. CBR often uses similarity measurements to identify the cases that are more relevant to the considered problem[3]. In fact, although there were some attempts to involve the CBR paradigm to deal with Fatawa issues [4], [5], these approaches are, however, based on syntax-based measurements. Indeed, syntax-based measurements have proven - in many cases - unsuccessful due to semantic issues that may occur. To overcome this limitation, we propose to build a domain ontology of a given domain to support the semantic similarity measurement. Measuring a distance between concepts is an essential process. Most methods used for measuring, they usually do not [6] take semantic for consideration [6].

In order to validate our proposal, we have implemented and tested a prototype to deal with fatawa in Islamic finance and banking transactions domain. Globally, the obtained results are promising and encouraging and thus show the effectiveness of the proposal.

The rest of this paper is structured as follows, section 2 provides some basic concepts around question-answering systems, CBR paradigm and ontologies. Section 3 gives details about the proposed architecture of the system. Section 4 summarizes and discusses some illustratives examples and scenarios. Finally, section 5 provides some conclusions and final remarks.

\section{BASIC CONCEPTS}

\subsection{Questionn answering system}

Question-answering (QA) systems in information retrieval are tasks that automatically answer the questions asked by humans in natural language using either a pre-structured database or a collection of natural language documents [7], [8]. In order to better understand what QA systems are, the associated terminology is firstly provided, namely Question Phrase, Question Type, Answer Type and Question Focus. The term Question Phrase is the part of the question that specifies what exactly is sought. The term Question Type refers to a categorization of the question regarding its purpose. The term Answer Type refers to a class of objects that the question is looking for. Finaly, the term Question Focus is the property or entity being searched by the question [9].

\subsection{Islamic finance and banking}

In last few decades, Islamic finance and banking (IFB) has grown exponentially and it is now regarded as one of the most important trends in the global financial industry. Indeed, that kind of financial transactions attracts not only Islamic communities, but also many people over all the world for many reasons, among others: i) making sound economic investment, ii) exchanging products, iii) satisfying people living in non-Muslim Countries. In IFB, financial and banking institutions do not make usury and interest-based transactions with their customers but rather to transactions that lead to benefits by taking into account the risk to result in some financial losses [10]. In fact, the compliance of IFB regulations may vary from one bank to another. This usually leads customers to ask some specific councils (e.g., Algerian Fatawa House) about the conformity of their products and services with IFB principles.

\subsection{Case based reasoning}

Case based reasoning (CBR) is an artificial intelligence paradigm that solves new problems by retrieving stored records of prior problem-solving episodes (cases) and adapting their solutions to fit new circumstances. Processing each episode provides a new case that is stored for future reuse, making learning a natural side-effect of the reasoning process [11]. The CBR can be very advantageous for a decision maker which knows a large number of cases and is able to index them so that the most relevant ones come to mind when needed [4]. 


\subsection{Ontology}

Ontologies play an important role for many knowledge-intensive applications [12]. They provide a number of useful features for intelligent systems, as well as for knowledge representation in general and for knowledge engineering processes [13]. Currently, ontologies are used to make information explicit and sharable. In addition, to further improve data and information management, one would create an ontologybased application that processes all knowledge related to a given topic. Such a process would involve knowledge modeling through an ontology [14].

\section{RELATED WORKS}

The literature review on studies involving assistance to Fatawa generation systems showed us that there is only a very small number of research-works. The authors [5] have proposed an intelligent Fatawa Question Answering system using SOPHIA-textual case-based reasoning (TCBR) which was firstly used in Patterson's work [15]. This is a subfield of case-based reasoning (CBR) in which knowledge sources (expertise) are available in textual format. It is based on the conditional probability distributions of terms within documents. The limitation of this system lies in the fact that SOPHIA-TCBR is not endowed with a mechanism to identify words' order, negation and synonyms and thus it lacks of objectiveness since these elements play a key role in interpretation of questions.

The authors [4] have designed an intelligent tool-called El Bayane-to give Fatawa for new situations, by using the Fatawa of past situations. The system delas with fatawa related to the field of drinking and smoking in Islamic legislation. It is also built around the CBR paradigm where the knowledge is organized into cases stored in a case-base. Then, an inference process is performed in order to find and reuse the appropriate Fatwa and its argumentation. Even so, this system retrieves only similar cases based on syntactic analysis and thus it does not consider the semantic aspect.

The aim targeted by this paper is twofold:

- processing Fatawa in IFB field to assist the Expert Mufti in his task and

- using a new semantic similarity assessment mechanism based on a domain ontology for IFB.

Thus, we develop an automatic QA system to deal with Fatawa requests by means of an intelligent case-based system that can store previous fatawa and retrieve them as needed. For this purpose, the casebased reasoning (CBR) paradigm is involved by using similarity measurements to identify the cases that are more relevant. And as syntax-based measurements have proven - in many cases - unsuccessful because of sematic issues, we build an ontology to support the semantic similarity measurement. It should be noted that our proposal is different from fatawa web sites for which users can either ask questions and wait for getting answers or search manually for fatwa from booklet through keywords.

\section{SYSTEM COMPONENTS}

\subsection{Fatawa question answering system architecture}

Islamic Fatwa is what the Islamic rules judge about an issue. When generating a fatwa, Muftis must have the document of prior fatawa and all updates given by expert scholars. This document keeps hundreds of millions of such Islamic Fatwa, searching the right fatwa may takes days. On the other hand, when, Imam (Mufti Novice) haven't the document of fatwa. Then, they could wrongly try to give fatwa. In principle, the fatwa must be given by Jurisprecedent (expert scholars). These reasons motivate us to create a knowledgebased system for assisting Mufti.

The architecture of the system shown in Figure 1 includes three components (case memory, Islamic finance domain ontology, system interfaces) and five modules (indexing module, extracting module, adaptation module, validation module and storage module). The system takes the description of the situation as input and provides an answer with arguments as output.

The proposed system is intended for both expert and novice (learner) Muftis. It saves fatawa in a case-base memory (i.e., all prior Fatawa) for further reuse. The expert Mufti can add, update or delete fatawa via a specific interface. In addition, both expert and learner Mufti can retrieve fatawa by interrogating the system via another interface that allows running queries on the specific fields. The system analyzes queries syntactically and semantically. The first version of this approache was proposed on [16]. 


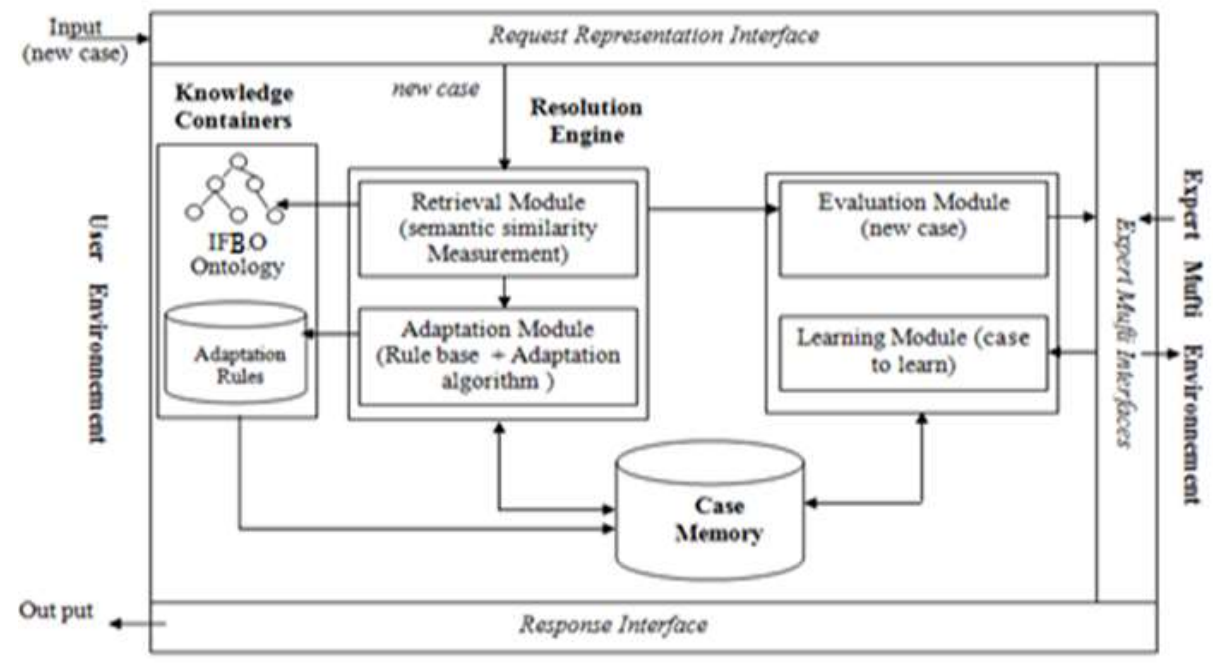

Figure 1. Fatawa system architecture

\subsection{Domain ontology}

The ontology reuse is highly recommended as it helps researchers and developpers to save time, efforts and costs [17]. In the context of IFB field, very few ontologies already exist; the most relevent are: Semantic-based Multilingual Islamic Finance Thesaurus [18] and I-FIKR Ontology. The former was used earlier (i.e., in past time) in the MIMOS web site: http://www.mimos.my/IFT\# and it is currently not available for reuse. The latter is not available as an open data since it is still under construction and therefore not ready for reuse. Accordingly, we built the Islamic Finance and Banking Ontology (IFBO) (see Figure 2), a domain reference ontology for IFB, by following the design process specified by Neon methodology [19]. This ontology provides a consensual sense for each word which helps in retrieving and learning from existing cases in order to endow the base with new cases. It is created for free reuse by making it available to users under the following link:

https://www.researchgate.net/publication/323454895_IFBO_Islamic_Finance_and_Banking_Ontolo gy For more details about IFBO ontology as well as the development process, the reader should refer to [20].

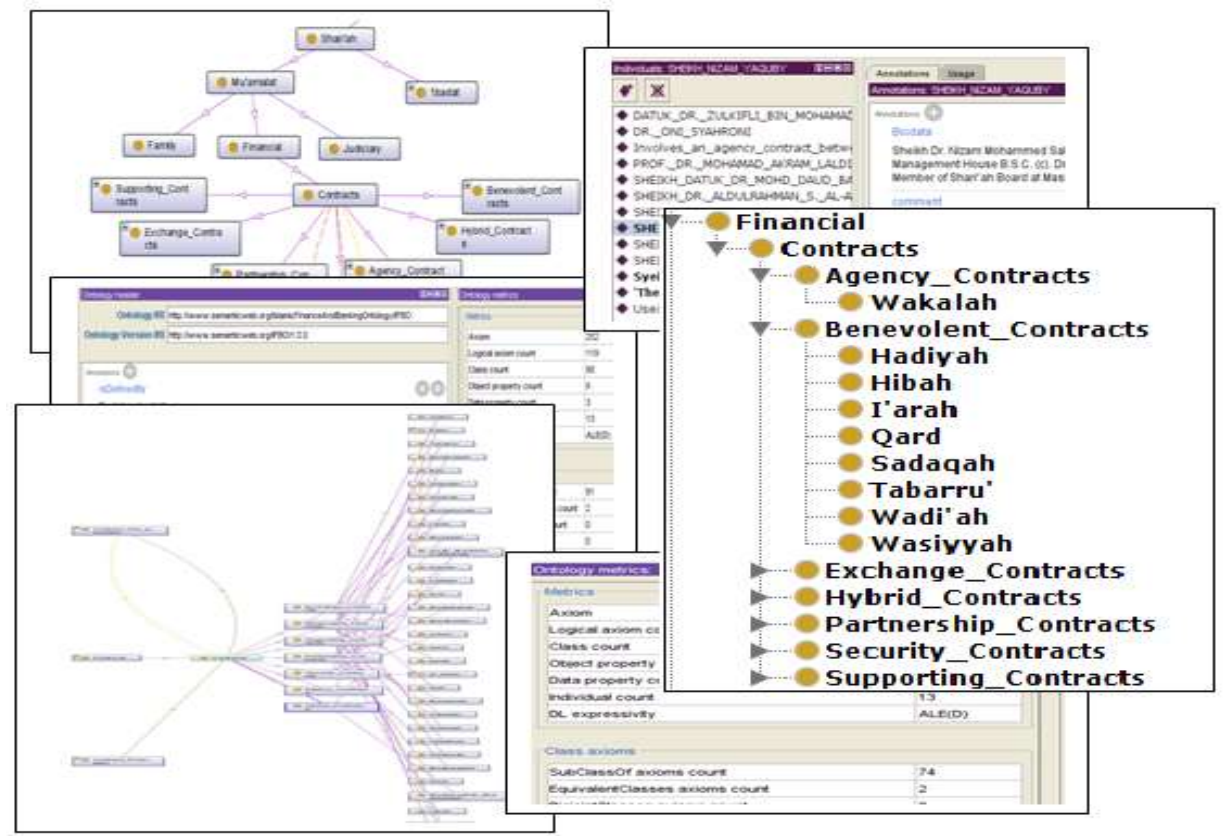

Figure 2. IFBO ontology 


\subsection{Case description}

A case is a contextualized piece of knowledge representing an experience. It contains the past lesson outlining the context of the case and the context in which the lesson can be used. A case can be an account of an event, a story, or a record typically comprising [21]. Regarding our QA system, the case contains two parts as shown in Figure 3.

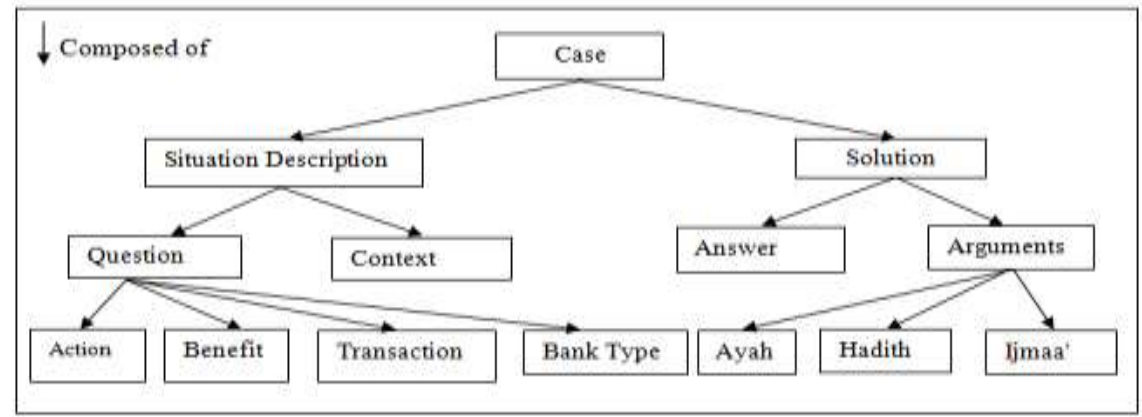

Figure 3. Case description

The problem description part (the query) that contains:

- Action: <Buy, Sale, Offer, Rent, Loan, .... >.

- Benefit Name: <Car, Apartment, Home, ...>.

- Contract: <Murabahah, Mudarabah, Leasing, Istisna'...>,

- Bank Type: < Conventional, Islamic, Window in conventional,>.

The solution description part (the answer).

\subsection{Case base}

Case-base is used to store previous and new learned cases. As reported in [22], there are several methods for memory organization:

- The flat organization (a flat memory): cases are sequentially stored one after the other in a simple list, an array, or a file.

- Shared feature Network: this regroups cases presenting similarities in one cluster. Hierarchies are formed when clusters are subdivided into under-clusters. The methods used in regrouping clustering are the ones used in machine learning.

- Discrimination Networks: the regrouping clustering made in shared feature networks leads to a discrimination. In this organization networks, every internal node is a question that discriminates according to the answer cases contained in the base. The most important questions are put in first.

In our QA system, cases are stored in a flat case memory given that the current number of cases leads to better performances.

\subsection{Inference cycle}

Reasoning modules are the operational part of the system: retrieval module, adaptation module, evaluation and learning module.

\subsubsection{Retrieval module}

When, a new problem (query) is posed and is described as the problem part of a new case. The semantic similarity measurement is computed between new case problem descriptors and old cases problem descriptors to identify the most similar cases to the new problem from the case memory (case base). The semantic similarity measurement assumed by the Application Ontology built before. It was integrated to the CBR cycle for improving their results of cases retrieval because the syntactic measurement often give fail. For example:

$$
\text { Problem description }=\langle\text { Action', benefit', transaction', Bank Type'>. }
$$

In this case, syntactic measurement give fail. Thus, the system should be able to select the case or set of cases with greater similarity to reuse the solution after possible adaptation. That is why, the application ontology is 
needed to asses similarity between the case problem descriptors. The proposed approach is detailed in [16] and summarized as follow:

- Syntactic measurement:

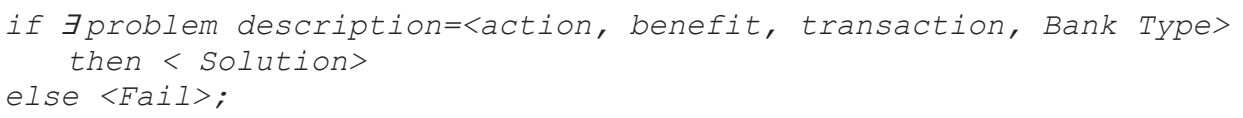

- Semantic measurement:

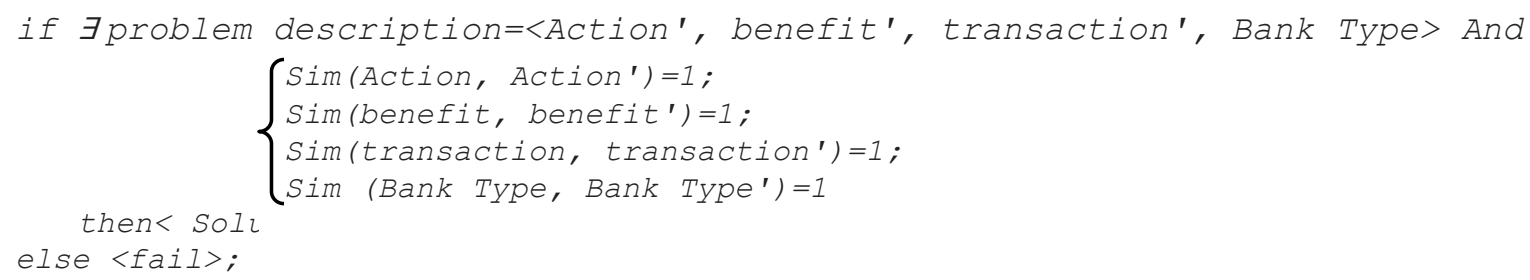

- Similarity attributes:

$$
\operatorname{Sim}\left(D, D^{\prime}\right)=\left\{\begin{aligned}
1 & \text { if }\left(D \text { same as } D^{\prime}\right) \text { or }\left(D \text { equivalent to } D^{\prime}\right) ; \\
& / / / \text { value of the new problem case } \\
& / / D^{\prime} \text { value of retrieved problem case. } \\
& \text { otherwise; }
\end{aligned}\right.
$$

\subsubsection{Average semantic measurement:}

The Average Similarity measurement (A-Sim) between new case problem descriptors (NDP) and old cases problem descriptors (ODP), in the proposed system, is given by:

where

$$
A-\operatorname{Sim}(N P D, O P D)=\sum_{j=1}^{n} \frac{\operatorname{Sim}\left(D, D^{\prime}\right)}{n}
$$

- j refers to a problem descriptors attribute.

- $\mathrm{n}$ refers to a number of descriptors attribute.

\subsubsection{Adaptation module}

The result of retrieving module is a set of cases with greater similarity. Then, the adaptation module reuses the solution of old cases retrieved after possible adaptation. This adaptation uses a set of base rules, the application ontology, and is performed by the adaptation Algorithm.

\section{- Rule Base}

The rule base contains 4 principals' rules as shown in table as shown in (Table 1).

Table 1. Rule base (excerpt)

\begin{tabular}{lll}
\hline Rul Descriptions & Conditions & Examples \\
\hline Rul D inverse of D' & D,D' instances of Act & (Sale, Bay) \\
Rul D sub class direct & $\mathrm{D}^{\prime}=$ Halal Benefit / & (Reality, Halal Benefit)/ \\
& $\mathrm{D}^{\prime}=$ Haram Benefit// & (Alcohol, Haram Benefit)/ \\
& $\mathrm{D}^{\prime}=$ Contracts & (Musharakah,Contracts) \\
Rul D sub class indirect of & $\mathrm{D}^{\prime}=$ Halal Benefit / & (Commercial Reality, Halal Benef \\
& $\mathrm{D}^{\prime}=$ Haram Benefit// & (Gelatine, Haram Benefit)/ \\
& $\mathrm{D}^{\prime}=$ Contracts & (Bay' Bi Thaman 'Ajil, Contracts) \\
Rul D instance of D' & - & (Terrain, Halal Benefit) \\
Rul Sim (D,D')=1 & - & (Car, Automobile) \\
\hline
\end{tabular}

- Adaptation algorithm

The adaptation Algorithm is the core of adaptation module, it consists of set of cases to be executed in dependent with the problem descriptors and based on the application ontology. 


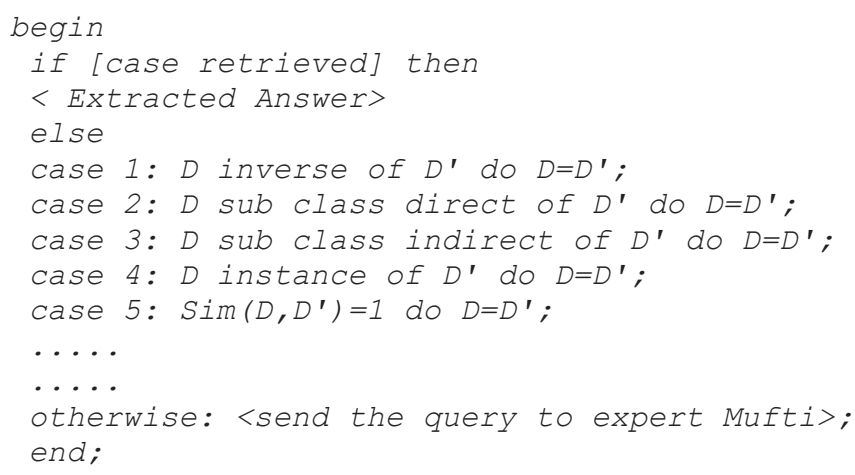

For example:

- User asked the question: what is the ruling on buying a truck by Murabaha through an Islamic bank?

- New problem description $=<$ Buy, Truck, Murabaha, Islamic Bank $>$;

- Three Hypotheses may suggest, as follow:

Hypothesis one: suppose that exists,

Old problem description $=\langle$ Buy, Truck, Murabahah, Islamic Bank>;

Then by semantic measurement: Murabaha is equivalent to Murabahah,

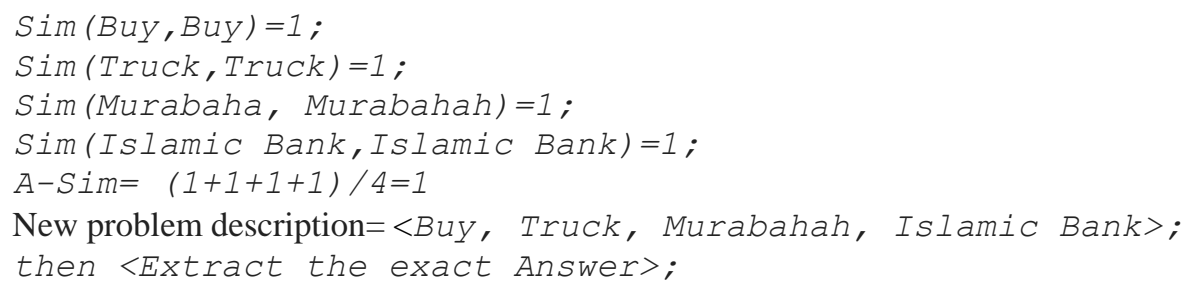

Hypothesis two: suppose that, after computing semantic similarity measurement between the both descriptors, the average similarity is between 0 and $1,(0<A-S i m<1)$. In this situation, the adaptation module search in the rule base for the appropriate rule.

From the ontology:

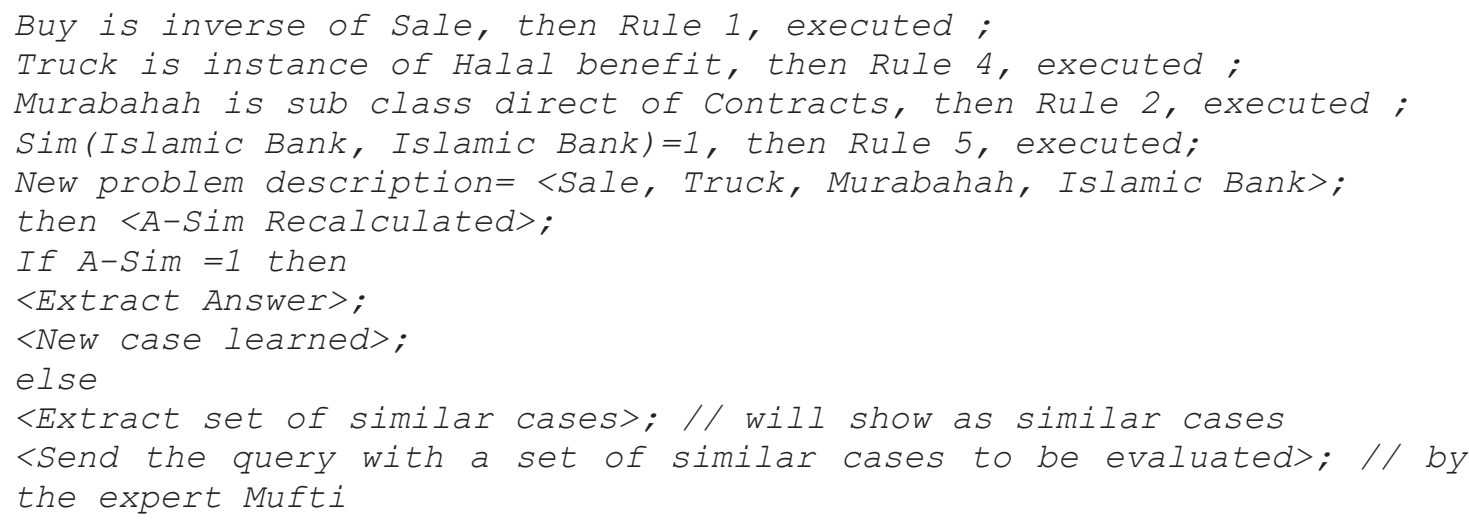

Hypothesis three: suppose that, after computing semantic similarity measurement no likeness between the both descriptors; all dimensions give zero $(A-S i m=0)$; In this situation, the adaptation module send this query to expert Mufti. For giving new answers (manual learning). And, show to the user a message: "Sorry there is no answer for your query, your request was sent to the expert Mufti. Please, try again after few days".

\subsubsection{Learning and evaluation module}

The Expert-Mufti enriches the case base and the application ontology when required. The Expert-Mufti has a specific interface to add, modify and deleting cases. His role is to evaluate the proposed answers for cases having between ( 0 and 1 ). He may validate them or generate new ones to make the system learn. The automatic learn is realized only when the Average Similarity $(A-S i m=1)$. 


\section{RESULTS: ILLUSTRATIVE EXAMPLE}

To validate this work, we have implemented a prototype of the proposed QA system. It consists in a multilanguage application developed using the Java language. In what follows, screenshots are illustrated in both English and Arabic languages. Three users' classes are considered: simple user (سائل) (is simple user a novice or learner Imam), expert Mufti (خبير) and administrator (مدير); Figure 4 shows the main panel.

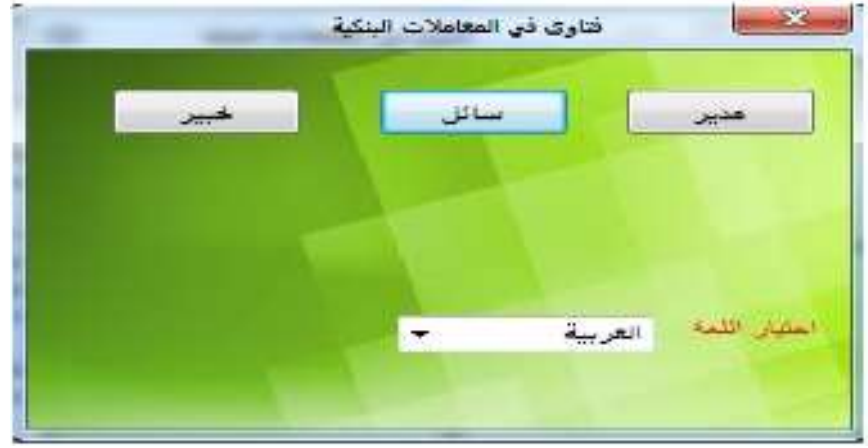

Figure 4. The main menu

It should be noted that the current version of the prototype does not allow users to interact with the system through questions formulated in natural languages. This lies to the fact that the use of natural languages may pose several problems related to natural language processing (NLP). Consequently, we have limited ourselves by imposing some restrictions on the way the questions are formulated since the main objective here is only to check the effectiveness of the approach.

- User space, the user space allows simple users to formulate their questions by specifying (see Figure 5):

a) The kind of question which can be: (What is the judgment? What is the punishment?): (ما حكم? ما حد) (م) (م)

b) The action (Buy, Rent, Sell, Mortage): (شر اء, كر اء, بيع ,رهن).

c) The benefit (Commercial location, House, Car):: (محل, منزل , سيارة): (منرة):

d) The type of contract (Murabaha, Musharakah, Mudharabah): (منزئة (مضة مضاربة, مشاركة).

e) The type of bank (conventional, Islamic): (تقليدي, إسلامي).

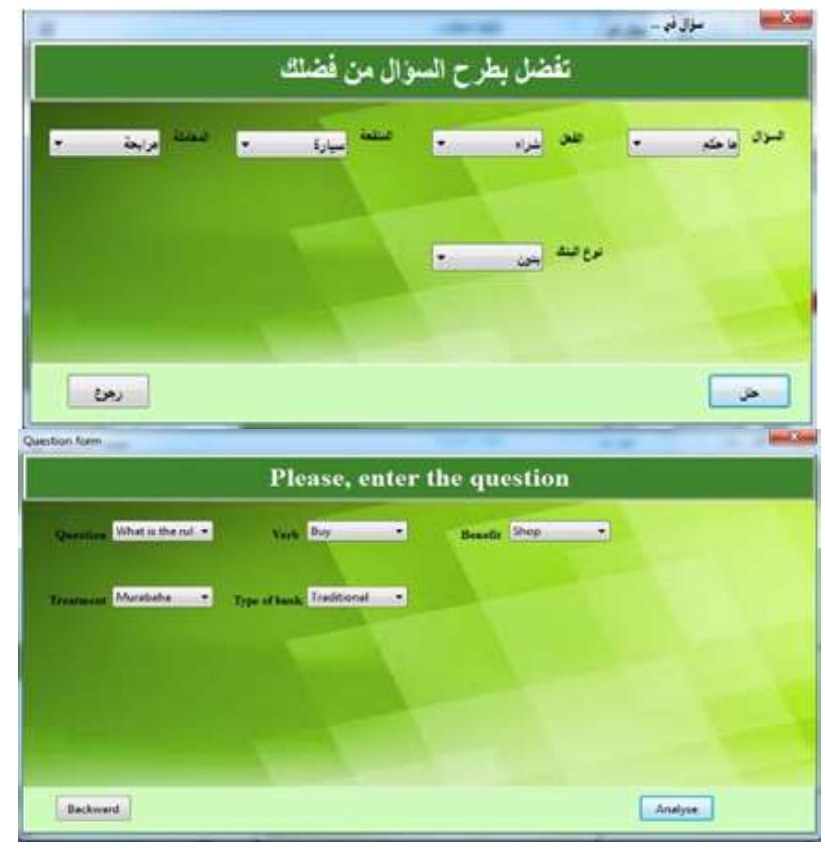

Figure 5. Question form 
Once the question is formulated, the user asks for the answer by clicking on the button (Analyze: ح $ل$ ). The result is shown in Figure 6.

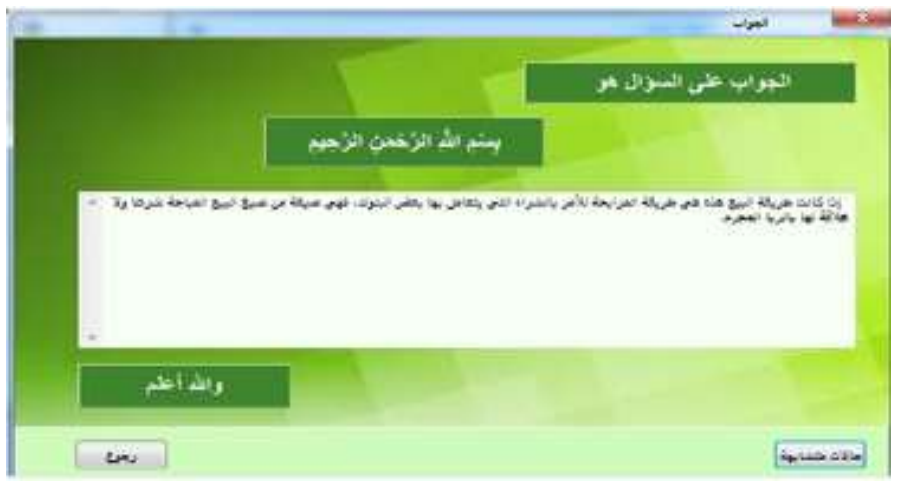

Figure 6. Response form

The system allows the simple user to take a look at the similar cases (Similar cases: (لحالات المتشابهة), as depicted in Figure 7.

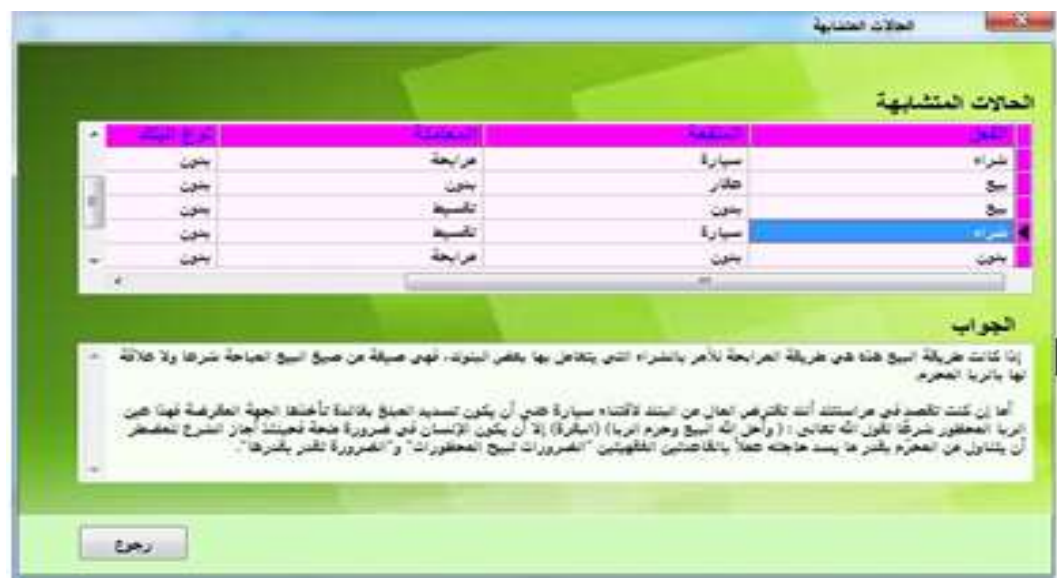

Figure 7. Similar cases form

- Administrator space

The administrator is responsible for setting-up and managing the case base before starting to use the QA system. At any time, he can browse the case base (see Figure 8).

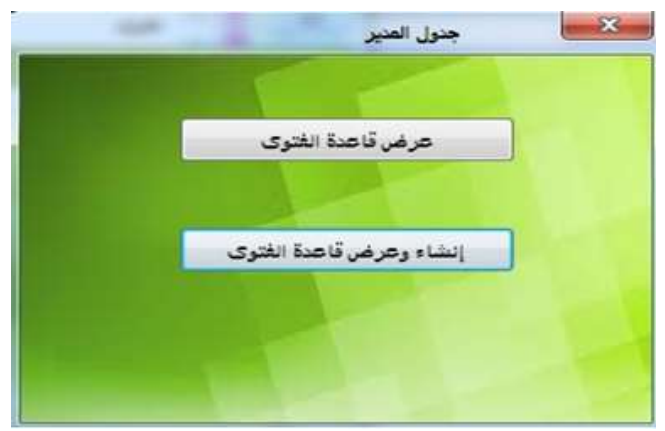

Figure 8. Administrator main menu 


\section{- Expert Mufti space}

The expert Mufti ensure three roles: add new questions to enrich the list of all questions, introduce answers to previously asked questions and finally modify a response in the case base, as given on Figure 9. Depending on the selected option, the system displays the corresponding screen as shown in Figures 10 and 11.
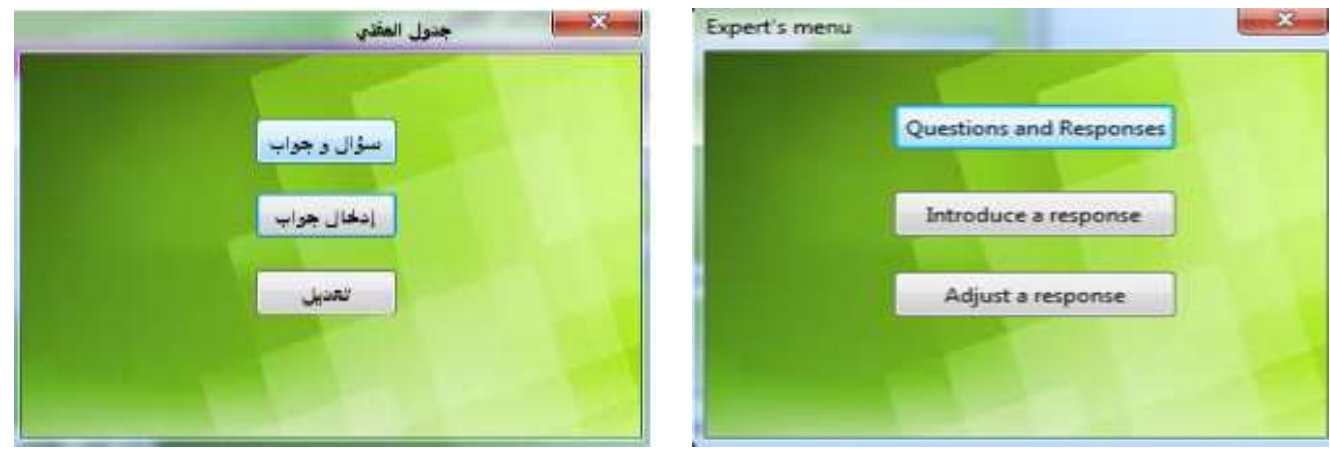

Figure 9. Expert mufti main menu

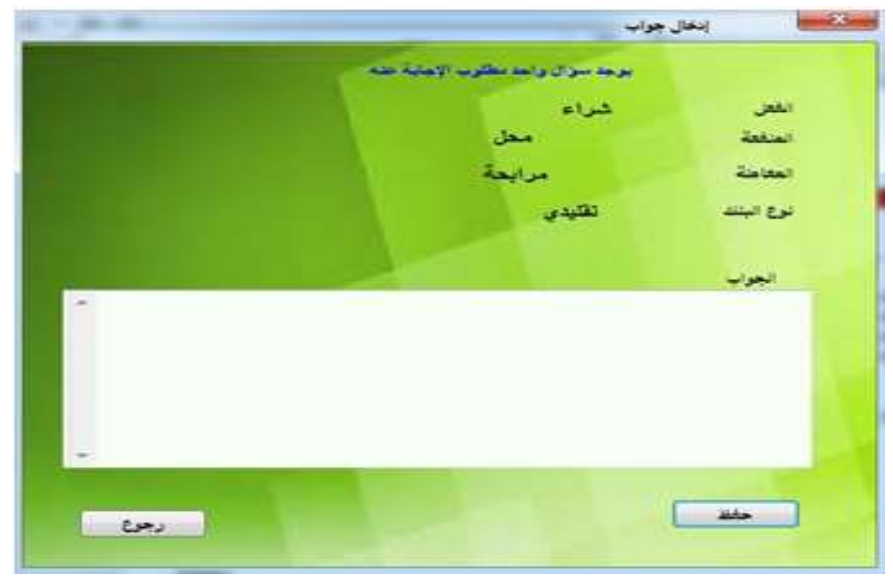

Figure 10. Introducing responses

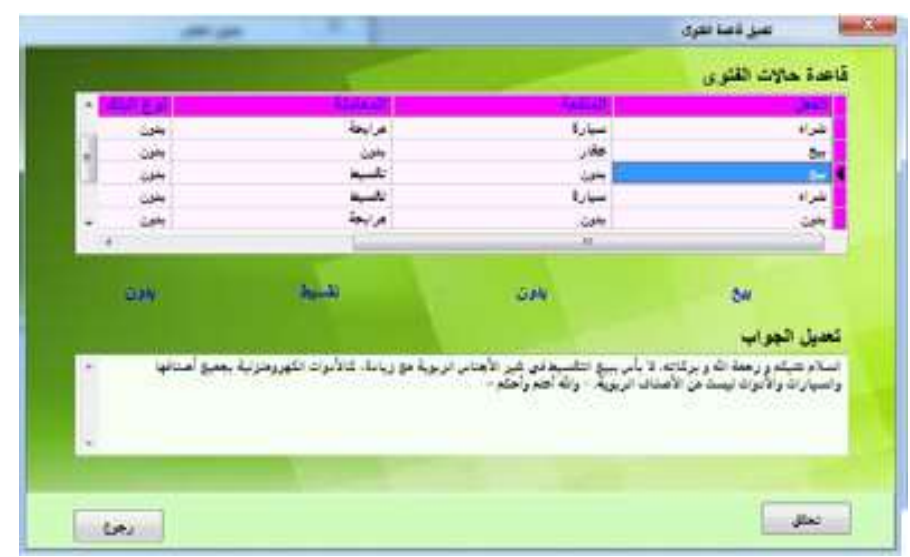

Figure 11. Adjusting response

\section{ASSESSMENT OF THE WORK}

Table 2.

Finally, we theoretically assess and compare our contribution with other related works, as given on 
Table 2. Comparative table of some existing approaches with our method

\begin{tabular}{|c|c|c|c|c|c|}
\hline Authors & Systems Proposed & Aims & Domains & $\begin{array}{l}\text { Paradigm } \\
\text { Used }\end{array}$ & $\begin{array}{c}\text { Semantic } \\
\text { Analyze }\end{array}$ \\
\hline $\begin{array}{l}\text { Nouaouria et } \\
\text { al. [23] }\end{array}$ & El Bayane & $\begin{array}{l}\text { Answering new questions } \\
\text { based on pre-answered ones }\end{array}$ & $\begin{array}{l}\text { Limited to Islamic } \\
\text { legislation on } \\
\text { drinking }\end{array}$ & CBR & No \\
\hline $\begin{array}{l}\text { Amari et al. } \\
{[4]}\end{array}$ & Intelligent tool for Mufti Assistance & $\begin{array}{l}\text { Answering new questions } \\
\text { based on pre-answered ones }\end{array}$ & $\begin{array}{l}\text { Limited to Islamic } \\
\text { legislation on } \\
\text { drinking }\end{array}$ & CBR & No \\
\hline $\begin{array}{l}\text { Elhalwany et } \\
\text { al. [5] }\end{array}$ & $\begin{array}{l}\text { Using Textual Case-based } \\
\text { Reasoning in Intelligent Fatwa QA } \\
\text { System }\end{array}$ & $\begin{array}{l}\text { Answering new questions } \\
\text { based on pre-answered ones }\end{array}$ & Open Domain & TCBR & No \\
\hline $\begin{array}{l}\text { Elhalwany et } \\
\text { al. [24] }\end{array}$ & $\begin{array}{l}\text { Enhancements to knowledge } \\
\text { discovery framework of SOPHIA } \\
\text { Textual Case-based Reasoning }\end{array}$ & $\begin{array}{l}\text { Answering new questions } \\
\text { based on pre-answered ones }\end{array}$ & Open Domain & TCBR & No \\
\hline $\begin{array}{l}\text { Salisu et } \\
\text { Hassan [25] }\end{array}$ & $\begin{array}{l}\text { Theoretical study no systems } \\
\text { proposed }\end{array}$ & $\begin{array}{l}\text { Review on Shariah } \\
\text { Regulatory framework of } \\
\text { Islamic finantial Instituitions }\end{array}$ & $\begin{array}{l}\text { Islamic } \\
\text { Finance and } \\
\text { Banking }\end{array}$ & None & No \\
\hline Our proposal & QA System Fatawa retrieval & $\begin{array}{l}\text { Answering new questions } \\
\text { based on pre-answered ones } \\
\text { With semantic controle }\end{array}$ & $\begin{array}{l}\text { Islamic } \\
\text { Finance and } \\
\text { Banking }\end{array}$ & CBR & Yes \\
\hline
\end{tabular}

\subsection{The advantages}

- Using of Case based reasoning paradigm wich is similar to human remembrance and reuse of old solutions.

- The key element of this work is the used of a domain ontology, which permits the semantic mesearments.

- Assist Imam in the process of retrieving and generating fatawa.

\subsection{The limitations}

- This system is limited to Islamic finance and banking domain.

- The use of frames form for asking a question, however in generally, questions about fatawa are asked in the form of stories not frames.

\section{CONCLUSION AND FUTURE WORK}

The main objective of this paper was to propose a question answering system for giving fatawa in Islamic Finance and banking for the Algerian fatawa house to help expert Mufti in his task of generating fatwa. The proposed system is built around a combination of the case-based reasoning paradigm and ontology-based computing. In particular, it uses semantic similarity measurements upon the Islamic Finance and Banking domain Ontology (IFBO). This ontology is in fact a key-element since it provides a domain vocabulary and allows the determination of degree of likeness between two classes or objects. The QA system has a case base memory that stores both prior fatawa and the new ones. Each case in the memory is represented by two parts: description and solution of the problem. To validate our proposal, a prototype was implemented and tested. Overall, the results are encouraging and satisfactory.

Our orientation in the future will be in three areas: to extend the application domain, to diversify sources of knowledge concerning questions presentation and jurisprudences conclusions; and to enlarge the scope of the tool via the web media.

\section{REFERENCES}

[1] A. H. Ghazali, al-Moustasfâ min 'Ilm al-OUssoul, Dar El Koutoub El Ilmia. 2000.

[2] R. G. C. Rocha, R. R. Azevedo, Y. C. Sousa, E. de A. Tavares, and S. Meira, "A Case-based Reasoning System to Support the Global Software Development," in Procedia Computer Science, vol. 35, 2014, pp. 194-202, doi: 10.1016/j.procs.2014.08.099.

[3] S. A. Diwan, "Proposed study on evaluating and forecasting the resident property value based on specific determinants by case base reasoning and artificial neural network approach," Indonesian Journal of Electrical Engineering and Computer Science (IJEECS), vol. 17, no. 3, pp. 1467-1473, Mar. 2020, doi: 10.11591/ijeecs.v17.i3.pp1467-1473.

[4] H. Amari, F. Atil, N. Bounour, and N. Nouaouria, "Intelligent tool for mufti assistance 2015," International Journal on Islamic Applications in Computer Science and Technology, vol. 3, no. 2, pp. 1-9, Jun. 2015.

[5] I. Elhalwany, A. Mohammed, K. Wassif, and H. Hefny, "Using textual case based reasoning in intelligent fatawa QA system," The International Arab Journal of Information Technology, vol. 12, No. 5, pp. 503-509, 2015. 
[6] S. Tongphu, B. Suntisrivaraporn, and P. Aimmanee, "Toward Semantic Similarity Measure Between Concepts in An Ontology," Indonesian Journal of Electrical Engineering and Computer Science (IJEECS), vol. 14, no. 3, pp. 1356-1372, Jun. 2019, doi: 10.11591/ijeecs.v14i3.pp1356-1372.

[7] A. Ansari, M. Maknojia, and A. Shaikh, "Intelligent question answering system based on Artificial Neural Network," 2016 IEEE International Conference on Engineering and Technology (ICETECH), 2016, pp. 758-763, doi: 10.1109/ICETECH.2016.7569350.

[8] A. C. O. Reddy and K. Madhavi, "Hierarchy based firefly optimized K-means clustering for complex question answering," Indonesian Journal of Electrical Engineering and Computer Science (IJEECS), vol. 17, no. 1, pp. 264-272, Jan. 2020, doi: 10.11591/ijeecs.v17.i1.pp264-272.

[9] M. A. Calijorne Soares and F. S. Parreiras, "A literature review on question answering techniques, paradigms and systems," in Journal of King Saud University-Computer and Information Sciences, vol. 32, no. 6, pp. 635-646, Jul. 2020, doi: 10.1016/j.jksuci.2018.08.005.

[10] N. Alam, L. Gupta, and B. Shanmugam, Islamic finance-A Practical Perspective, 1st edition. New York, NY: Springer Berlin Heidelberg, 2017.

[11] D. B. Leake, "Case-based reasoning," A Companion to Cognitive Science, John Wiley and Sons Ltd., 2003, doi: 10.1002/9781405164535.ch36.

[12] M. C. Suárez-Figueroa, NeOn Methodology for Building Ontology Networks: Specification, Scheduling and Reuse. IOS Press, 2012.

[13] D. Gaševic, D. Djuric, and V. Devedžic, Model Driven Engineering and Ontology Development. Springer Science \& Business Media, 2009.

[14] F. S. Utomo, N. Suryana, and M. S. Azmi, "New instances classification framework on Quran ontology applied to question answering system," TELKOMNIKA (Telecommunication Computing Electronics and Control), vol. 17, no. 1, Feb. 2019, pp.139-146, doi: 10.12928/telkomnika.v17i1.9794.

[15] D. Patterson, N. Rooney, M. Galushka, V. Dobrynin, and E. Smirnova, "SOPHIA-TCBR: A knowledge discovery framework for textual case-based reasoning," Knowledge-Based Systems, vol. 21, no. 5, pp. 404-414, Jul. 2008, doi: 10.1016/j.knosys.2008.02.006.

[16] K. Benlaharche and N. Nouaouria, "Ontology based Similarity for Case Based Reasoning in Islamic Banking," International Journal on Islamic Applications in Computer Science and Technology, vol. 6, no. 2, Oct. 2018, [Online]. Available: http://www.sign-ific-ance.co.uk/index.php/IJASAT/article/view/2013.

[17] V. K and K. Nk, "Effective Feature Set Selection and Centroid Classifier Algorithm for Web Services Discovery," Indonesian Journal of Electrical Engineering and Computer Science (IJEECS), vol. 5, no. 2, pp. 441-450, Feb. 2017, doi: 10.11591/ijeecs.v5.i2.pp441-450.

[18] A. Mamadolimova, et al., "Semantic-based Multilingual Islamic Finance Thesaurus," Conference: eKNOW 2014: The Sixth Int. Conf. on Information, Process, and Knowledge Management Barcelona, 2014, pp. 44-50.

[19] M. C. Suárez-Figueroa, A. Gómez-Pérez, and M. Fernández-López, "The NeOn Methodology framework: A\&nbsp; scenario-based methodology for ontology\&nbsp; development," Applied Ontology, vol. 10, no. 2, pp. 107-145, Jan. 2015, doi: 10.3233/AO-150145.

[20] B. Keltoum, N. Nabila and M. Djamel, "Towards reference ontology for islamic finance and banking," 2018 International Conference on Information and Communication Technology for the Muslim World (ICT4M), 2018, pp. 74-79, doi: 10.1109/ICT4M.2018.00023.

[21] I. Watson, Applying Case-Based Reasoning: Techniques for Enterprise Systems, 1 edition. San Francisco, USA: Elsevier Science, 1997.

[22] J. Kolodner, Case-based reasoning. San Francisco, CA, USA: Morgan Kaufmann Publishers Inc., 2014.

[23] N. Nouaouria, F. Atil, M. T. Laskri, and D. Bouyaya, "A case based tool as intelligent assistance to mufti," The Arabian Journal for Science and Engineering, vol. 31, no. 1B, pp. 75-87, 2006.

[24] I. Elhalwany, A. Mohammed, K. T. Wassif, and H. A. Hefny, "Enhancements to knowledge discovery framework of SOPHIA textual case-based reasoning," Egyptian Informatics Journal, vol. 15, no. 3, pp. 211-220, Nov. 2014, doi: 10.1016/j.eij.2014.10.002.

[25] A. Salisu and S. A. Hassan, "A review on sharia regulatory framework (SRFW) of islamic financial institutions (IFIS) Malaysia based on islamic spiritual qualities," Journal of Islamic, Social, Economics and Development (JISED), vol. 5, no. 30, pp. 23-31, 2020.

\section{BIOGRAPHIES OF AUTHORS}

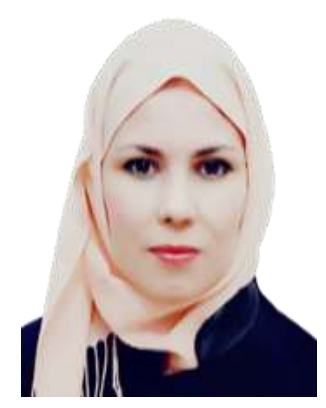

Benlaharche Keltoum is an assistant professor in department of computer science at Ecole Normale Supérieure (ENS-Kouba), Algeria. She received her Magister degrees from Ecole Supérieure d'Informatique in the field of information systems. Main research topics of Benlaharche include semantic web, artificial intelligence, case-based reasoning, Islamic finance and banking, Fatawa system. She has supervised numerous undergraduate research projects. 


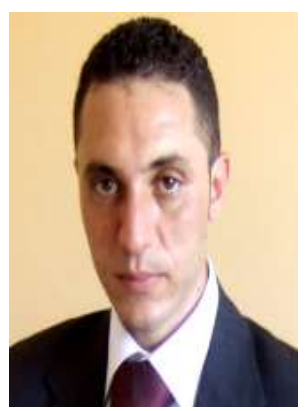

Zakaria Laboudi is a Lecturer in the field of computer science at the University of Oum ElBouaghi, Algeria. He is currently a member of the MoVéVaSiS research-team within the RELA(CS)2 Laboratory. He holds a PhD degree in computer science from University of Constantine2, Algeria. Previously, he joined the SCAL group within the MISC laboratory at the University of Constantine2, Algeria for the period from 2010 to 2018, in which he was invited to collaborate in several research projects and tasks. His current research interests include artificial intelligence, machine learning, optimization and meta-heuristics, ontologybased computing and context-aware pervasive systems.

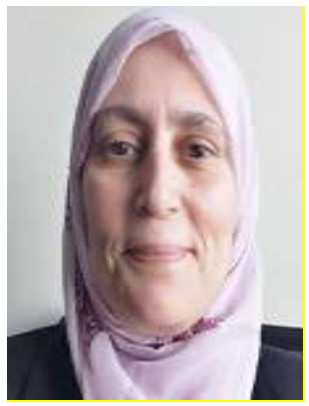

Nabila Nouaouria currently works at computer science departement, Badji Mokhtar-Annaba University, Algeria. Nabila has two PhD, the first one was from Badji Mokhtar university in 2006 and the second one was from Quebec university, Montréal in 2013. She does research in Higher Education, Algorithms and Artificial Intelligence, swarm optimization, case-based reasoning.

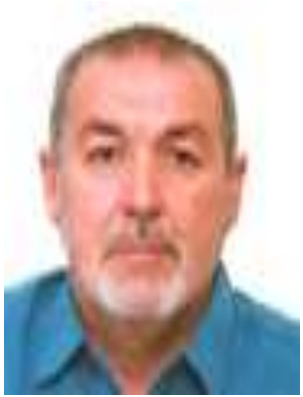

Djamel Eddine Zegour, Professeur of computer science and the Head of LSCI Laboratory at École Supérieure d'Informatique (ESI Ex INI) Algiers. His research of interest includes and not limited to advanced data structure, Compilation, Quran applications, NLP, Algorithms. He has two books and he is the inventor of $\mathrm{Z}$ langage and $\mathrm{Z}$ compilator. 